\title{
Feel, Think, Teach - Emotional Underpinnings of Approaches to Teaching in Higher Education
}

\author{
Robert Kordts-Freudinger ${ }^{1}$ \\ ${ }^{1}$ Psychology Department, Paderborn University, Germany \\ Correspondence: Robert Kordts-Freudinger; Psychology Department, Paderborn University, D-33098 Paderborn, \\ Germany. Tel: 49-5251-60-2904 \\ Received: December 28, 2016 \\ Accepted: January 16, 2017 \\ Online Published: January 18, 2017 \\ doi:10.5430/ijhe.v6n1p217 \\ URL: http://dx.doi.org/10.5430/ijhe.v6n1p217
}

\begin{abstract}
The paper investigates relations between higher education teachers' approaches to teaching and their emotions during teaching, as well as their emotion regulation strategies. Based on the assumption that the approaches hinge on emotional experiences with higher education teaching and learning, three studies assessed teachers' emotions, their emotion regulation strategies and their approaches to teaching with questionnaires. Study 1 , with $n=145$ German university teachers and teaching assistants, found relations between positive emotions and the student-oriented approach to teaching, but not with negative emotions. In addition, cognitive reappraisal and expressive suppression were related to the student-oriented approach. Study 2, with $n=198$ German teachers, replicated these findings and, in addition, found relations between perspective taking, empathic concern and personal distress, and the student-oriented approach. Study 3, with $n=76$ Australian and New Zealand teachers, again replicated and extended the findings by establishing a relation between negative emotions and the content-oriented approach to teaching. The results of all studies together indicate a significant emotional component of the approaches to teaching. Positive emotions are not only directly related to the student-oriented approach, but also partially mediate the relation between cognitive reappraisal and the student-oriented approach. This link seems to generalize to emotional components of empathy. In addition, the cultural-educational context seems to moderate the relations between negative emotions and the content-oriented approach to teaching. Limitations and directions for future research and educational practice are discussed.
\end{abstract}

Keywords: University teacher, Emotions and emotion regulation, Approaches to teaching, Empathy, Cultural context

\section{Teaching with Emotions}

Although "emotions are at the heart of teaching" (Hargreaves, 1998, p. 835), there is a surprising lack of empirical studies on teachers' emotions in higher education. This study aims at expanding the knowledge base about university teachers' emotions. The study specifically investigates the relations between teachers' emotions and their approaches to teaching.

\subsection{Approaches to Teaching}

Although researchers still debate the very structure and nature (e.g., Kane, Sandretto \& Heath, 2002) and measurement of these approaches (e.g., Meyer \& Eley, 2006), most researchers agree on three aspects. First, approaches to teaching are typically considered a set of beliefs and strategies concerned with teaching (e.g., Kember, 1997; Kember \& Kwan, 2000; Trigwell \& Prosser, 1996, 2004). Second, researchers typically define approaches to teaching as a set of teachers' teaching strategies and underlying intentions (e.g., Trigwell \& Prosser, 1996). Third, researchers typically distinguish between a student-oriented (or student-focused) from a content-oriented (or teacher-focused) approach to teaching. Whereas a strong student orientation implies that the teacher focusses on her students' learning in the sense of facilitating their conceptual development and their conceptual change, a strong teacher orientation implies an intention towards imparting or transmitting information by the students (e.g., Kember \& Kwan, 2000; Trigwell \& Prosser, 1996). Research on approaches to teaching has consistently shown that approaches are relevant for teaching behaviors and for student learning (e.g., in the German-speaking context, Braun \& Hannover, 2008; Johannes \& Seidel, 2012). It is not clear, however, how approaches to teaching may relate to other, non-cognitive constructs, such as emotions. The following paragraphs will elaborate the findings on higher education teachers' emotions. 


\subsection{Higher Education Teachers' Emotions}

Few studies have investigated higher education teachers' emotions. Meanwell and Kleiner (2014) and Stupnisky, Pekrun and Lichtenfeld (2014) focused on new teachers' emotions. Stupnisky and colleagues (2014), for instance, found that new teachers experience more enjoyment and pride, and less anxiety, guilt and helplessness during teaching situations than when engaging in research activities (cf. Hagenauer \& Volet, 2013). These studies point to the importance of positive emotions in teaching, i.e., experiencing emotions during giving a lecture, yet they leave open the relevance of teachers' emotions for their teaching, i.e., emotions' relevance for their thinking and behavior. Two studies so far have investigated this latter issue by relating teachers' emotions to their approaches to teaching. Postareff and Lindblom-Ylänne (2011) conducted interviews with university teachers and found that consonant (internally consistent) learning-focused teachers experienced positive emotions most often. By contrast, consonant (consistent) content-focused teachers experienced neutral or negative emotions most often. These findings imply a relation between the experience of positive or negative emotions during teaching and teachers' approaches to teaching.

Trigwell (2012) tested the relation between emotions and approaches to teaching quantitatively. By employing an Emotions in Teaching Inventory, he found significant positive relations between the student-oriented approach to teaching and the experience of positive emotions during teaching. The more strongly teachers experienced the positive emotion of pride, the stronger their focus on their students' learning. In addition, he found positive relations between a content-oriented approach and the experience of negative emotions, such as frustration and anxiety. The findings by Trigwell (2012) and Postareff and Lindblom-Ylänne (2011) indicate the relevance of teachers' emotions for teaching.

\subsection{Higher Education Teachers' Emotion Regulation}

In addition to the experience of emotions, approaches to teaching may also be related to the regulation of emotions. Although no study has targeted this relation so far, some recent studies investigated higher education teachers' emotion regulation.

Based on sociological theory, emotional labor (e.g., Grandey, 2000) has been discussed as a requirement that the university expects its teachers to regulate their emotion expression. Constanti and Gibbs (2004), in interviews with higher education teachers in Cyprus, found that these conform to the expected behaviour by suppressing the expression of negative emotions and by increasing the expression of positive emotions, especially towards their students, a finding that was replicated by Hagenauer and Volet (2014a) with Australian teachers. Mendzheritskaya, Hansen and Horz (2015) investigated cultural determinants of emotional expression. They found that Russian higher education teachers showed negative emotions more openly than German teachers did (Mendzheritskaya et al., 2015). In a similar vein, Hagenauer, Gläser-Zikuda and Volet (2016) compared Australian to German university teachers. Whereas Australian teachers valued the expression of positive emotions higher, German teachers by contrast valued the expression of negative emotions, especially anger, more. In sum, culture-specific display rules, i.e., the rules that explicate the norms of expressing emotions, seem to influence higher education teachers' emotion expression during teaching. This surface acting strategy (Grandey, 2000), however, seems to place a burden on the teachers employing them. With Chinese higher education teachers who responded to questionnaires, Zhang and Zhu (2008) found that the surface acting strategy of emotional labor was positively related to several burnout subscales and negatively to satisfaction (cf. Grandey, 2003). The deep strategy of "managing feelings" (Grandey, 2000, p. 97) seems more fruitful, as indicated by positive relations to satisfaction and negative relations to burnout in Zhang and Zhu's (2008) study.

Emotion regulation theory by Gross and John (2003) seems well suited for the investigation of different emotion regulation strategies. Based on based on research neurophysiological bases of emotions (e.g., Ochsner \& Gross, 2008), this approach is explicit about the psychological processes underlying the regulation. It explicitly distinguishes a series of antecendents that lead to an emotional response (situation selection, attention, cognitive interpretation) from the very emotional response (on behavioural, experiential and physiological levels) itself. Emotion regulation can take place at all of the pre-response stages: People may change the emotion-eliciting situation, they may modify this situation, they may deploy their attention towards or away from specific aspects of the situation, or they may cognitively change its meaning. One of these antecedent-focused strategies has particularly gained research attention. Cognitive reappraisal includes cognitive activities that aim at changing the situation's meaning for the person (e.g., Gross, 1998, 1999). Importantly, compared with expressive suppression, which, as a response modulation strategy roughly equals the surface acting cited above, reappraisal positively influences both short- and long-term health, well-being and social abilities. Expressive suppression, by contrast, is related to less functional social relations and worse health and cognitive conditions (e.g., Gross, 2002; Gross \& John, 2003; John \& 
Gross, 2004).

The present studies will thus inform about two sets of correlates of approaches to teaching: teachers' emotion frequency during teaching and their emotion regulation strategies. Study 1 investigates the experience of higher education during teaching, the use of cognitive reappraisal and of expressive suppression and relations between all three constructs; Study 2 tries to replicate these findings and extend them by investigating one possible mechanism underlying the relation between emotion regulation and approaches to teaching; Study 3, finally, focusses on the approaches' relations with negative emotions by extending the findings to a second cultural context.

\section{Study 1}

As discussed above, little is known about which emotions are experienced by university teachers during their teaching. Defining emotions as multi-component processes consisting of affective (experiential or feeling), cognitive, physiological, behavioral and expressive components (e.g., Scherer, 2005), the literature offers two ways to assess higher education teachers' emotions quantitatively. One option would be the use of Trigwell's (2012) questionnaire for assessing the frequency of teachers' emotions. It uses items that ask for the experience of specific emotions during teaching. Its validity, however, seems questionable. First, some items include descriptions that are typically not considered to be emotions. For instance, most researchers would agree that "When I consider what students can do with what I have taught them I feel motivated" (Item 8, Trigwell, 2012) assesses an aspect of (intrinsic) motivation, but not of emotion. Second, the questionnaire items lack emotions that emotion scientists typically discuss, such as guilt, surprise or relief. Third, Trigwell's (2012) items also include the situations in which teachers experience the emotions, for instance, "when preparing lessons" (Item 2, Trigwell, 2012). This specific situation, however, may not be typical for teachers' emotions. Grading student work or oral examinations are likely to be more emotion-eliciting for both students and teachers.

Another option for assessing emotions is the use of Stupnisky and colleagues' (2014) emotion questionnaire. Based on a qualitative study, these authors have developed a measure that asks participants to indicate to what extent they experienced ten distinct emotions during their teaching in the last year. The wording of this questionnaire, however, seems to confound emotional intensity with their frequency, the two of which follow distinct mechanisms and yield different results (e.g., Goetz, Zirngibl, Pekrun \& Hall, 2003). The current study used a questionnaire with a clear focus on emotional frequency.

In addition to the assessment of the frequency of teachers' emotions, Study 1 estimated the relation between emotions and approaches to teaching. The study in particular intended to replicate the quantitative findings by Trigwell (2012), who found positive correlations between positive (negative) emotions and a student-oriented (content-oriented) approach. For the first time, Study 1 also aimed at estimating the relation between emotion regulation strategies and approaches to teaching. For this aim, it chose two of the prototypical regulation strategies: cognitive reappraisal and expressive suppression (e.g., Gross \& John, 2003). Reappraisal is a typical antecedent-related regulation strategy, whereby people indirectly influence their emotions by influencing the way they think about situations. Suppression, by contrast, includes the change of one specific emotion reaction component, namely, expression.

The study sought answers to the following research questions:

Research Question 1: Do positive emotions and negative emotions form two separate factors within the emotion questionnaire?

Research Question 2: Are positive (negative) emotions correlated to a student-oriented (content-oriented) approach to teaching?

Research Question 3: Are emotion regulation strategies (cognitive reappraisal and expressive suppression) correlated to approaches to teaching (student-oriented and content-oriented approaches)?

\subsection{Methods}

\subsubsection{Sample}

The author sent e-mails with the link to an online survey that contained several questionnaires via several academic development e-mail lists to university teachers of all ranks (named teachers hereafter) and student teaching assistants of Paderborn University, a mid-sized Western German university, in 2012. $N=145$ respondents completed all parts of the questionnaires, among them $n=64$ university teachers (academics of all ranks, 38 female) and $n=81$ student teaching assistants (38 female). Teachers and teaching assistants did not differ with respect to their gender distribution, $\mathrm{X}(1 ; 145)^{2}=2.23, p=.14$. 


\subsubsection{Questionnaires}

Respondents answered items, among others, about their gender, teaching experience (in semesters), their official status and their departmental associations. In addition, they completed the following questionnaires. First, they completed the Approaches to Teaching Inventory (ATI; Trigwell \& Prosser, 2004, translated by Braun \& Hannover, 2008). The ATI assesses university teachers' conceptual-change/student-focused approach (five items, Cronbach $\alpha$ $=.71$ ) and their information-transmission/teacher-focused approach (six items, $\alpha=.58$ ). Second, they completed a set of items about the frequency of experiencing specific emotions during their teaching (14 items). Participants indicated the frequency with which they experienced one specific emotion during their teaching activities, on a five-point-scale (never, rather seldom, sometimes, frequently, quite often). Emotion items included joy/enjoyment, contentment, hope, pride, relief, compassion, surprise, anger, boredom, guilt, frustration, anxiety, hopelessness and sadness. Emotion items had been selected based on their prevalence in previous research on academic emotions (e.g., Stupnisky et al., 2014; Trigwell, 2012; Pekrun et al., 2011), completed by contentment, compassion and surprise. Contentment was added because of its lower-arousal nature, which could render it more frequent than joy/enjoyment; compassion was included because of the relevance of caring for school teaching (e.g., Teven, 2007); and surprise was included because of its ambivalent affective nature (e.g., Topolinski \& Strack, 2015). Third, they completed the Emotional Regulation Questionnaire (ERQ, Gross \& John, 2003, translated by Abler \& Kessler, 2009). The ERQ assesses the participant's self-reported use of the emotion regulation strategies of cognitive re-appraisal (six items, $\alpha$ $=.81$ ) and expressive suppression (four items, $\alpha=.72$ ). In order to enhance the specificity of the teaching domain, instructions asked participants to indicate the emotion regulation strategies employed during their teaching.

\subsection{Results}

\subsubsection{Status, Teaching Experience and Departmental Associations}

University teachers included ten professors (full and junior), 44 scientific staff, four postdoc researchers and 6 part-time teaching staff. As expected, university teachers $(M=10.65$ semesters, $S D=14.12)$ had more teaching experience than teaching assistants $(M=2.51$ semesters, $S D=1.78), F(1,139)=25.77, p<.001, \eta^{2}=.16$. They also differed with respect to their departmental associations, $\mathrm{X}(2 ; 145)^{2}=10.52, p<.01$. While the sample included nearly no teachers from the economics department (Humanities and Social Sciences $n=28$, Economics $n=2$, STEM departments $n=51$ ), teaching assistants from the economics department were present in the sample (humanities and social sciences $n=26$, economics $n=10$, STEM $n=28$ ).

\subsubsection{Emotions in Teaching}

Participants indicated that they most often experienced contentment $(M=4.05, S D=0.70)$, joy/enjoyment $(M=3.93$; $S D=0.76)$ and pride $(M=3.51, S D=0.99)$. Among the negative emotions, they most often experienced frustration $(M=2.17, S D=0.99)$, anger $(M=2.06, S D=0.95)$ and boredom $(M=1.92, S D=0.86)$.

In order to answer Research Question 1, the emotion data were analysed with an exploratory factor analysis. The principal component analysis with varimax rotation and listwise case exclusion yielded a two-component structure. The two-factor solution explained $41.09 \%$ of the variance.

Table 1. Item Loadings Resulting from the Principal Component Analysis

\begin{tabular}{lll}
\hline Item & Factor 1 & Factor 2 \\
\hline Frustration & .74 & -.09 \\
Hopelessness & .72 & -.09 \\
Sadness & .71 & .01 \\
Anger & .60 & -.08 \\
Guilt & .60 & .07 \\
Anxiety & .59 & .04 \\
Boredom & .19 & -.24 \\
Hope & .06 & .79 \\
Joy / Enjoyment & -.25 & .70 \\
Pride & -.17 & .66 \\
Contentment & -.36 & .60 \\
Relief & .25 & .58 \\
Compassion & .25 & .48 \\
Surprise & .03 & .41 \\
\hline
\end{tabular}


The emotion items fit a two-factor structure, with one exception. Boredom had a low loading on the negative emotions factor, in addition to its negative loading on the positive emotions factor. Recent research has shown that several types of boredom may exist (e.g., Goetz et al., 2014), particularly a differentiation between low- and high-arousal boredom types. It is likely that the present participants focused on the low-arousal type of boredom when answering the questionnaire, which may have reduced the negative emotional intensity associated with it. Still, boredom was included in the negative emotions factor, as previous research has treated it as negative emotion (e.g., Stupnisky et al., 2014).

Relief and compassion loaded on both the positive and the negative emotion factors. These two emotions are of an ambivalent emotional-motivational nature. Relief, for instance, is considered an avoidance-related emotion (having strong relations with negative valence) with simultaneous positive valence (e.g., Deutsch, Smith, Kordts-Freudinger \& Reichardt, 2015). Compassion is ambivalent, too, in that it entails a (positive) reaction to somebody else's negative suffering and motivates helping to relieve the suffering (e.g., Goetz, Keltner \& Simon-Thomas, 2010). With this definition, compassion is close to mainly negative emotions that arise from negative outcomes (e.g., Goetz et al., 2010).

All emotion items were collapsed into mean indices for positive emotions and for negative emotions separately. The resulting positive emotion index had a mean of $M=3.43, S D=0.58, \alpha=.71$; the negative emotion index had a mean of $M=1.73, S D=0.51, \alpha=.71$. Positive emotions were stronger than negative emotions, $F(1,144)=639.34, p<.01$, $\eta^{2}=.82$, as indicated by a repeated-measures analysis of variance (ANOVA).

\subsubsection{Relations between Emotions, Emotion Regulation and Approaches to Teaching}

In order to answer Research Questions 2 and 3, in a first step, approaches to teaching data were analysed by calculating means for the student-oriented approach $(M=3.30, S D=0.72)$ and the content-oriented approach $(M=$ 3.61, $S D=0.69$ ). A repeated-measures ANOVA yielded that the content-oriented approach was stronger than the student-oriented approach, $F(1,144)=12.26, p<.01, \eta^{2}=.08$. The ERQ resulted in a collapsed score for cognitive re-appraisal $(M=4.36, S D=1.12)$ and for expressive suppression $(M=3.82, S D=1.19)$. A repeated-measures ANOVA showed that reappraisal was higher than suppression, $F(1,144)=13.91, p<.01, \eta^{2}=.09$.

In further steps, correlations were calculated between emotions, emotion regulation strategies and approaches to teaching. These analyses revealed positive correlations between positive emotions, emotion reappraisal and the student-oriented approach.

First, positive emotions were related to the student-oriented teaching approach, $r(143)=.32, p<.001$. The more often the participants experienced positive emotions during their teaching, the stronger their student-orientated approach to teaching. However, there was no relation with either negative emotions or the content-oriented approach, all $|r|<.16$, all $p \mathrm{~s}>.06$. This result replicated Trigwell's (2012) finding for positive emotions, while not replicating the relation between negative emotions and the content-oriented approach.

Second, positive emotions were related to cognitive reappraisal, $r(143)=.18, p=.03$, but not to expressive suppression, $r(143)=-.10, p=.23$. Gross and John (2003) found the same result for reappraisal, indicating its effectiveness in terms of increasing positive emotions. Their results, however, also indicated a negative relation between suppression and positive emotions, which was not replicated in the present data set.

Third, the student-oriented approach was positively correlated to cognitive reappraisal, $r(143)=.34, p<.001$, and negatively to expressive suppression, $r(143)=-.19, p=.02$. The former finding could, however, be explained by the interrelations between positive emotions, cognitive reappraisal and the student-oriented approach. Positive emotions could mediate the relation between the student orientation and reappraisal. In order to test this possibility, the author conducted an additional regression analysis. This analysis followed the procedure proposed by Baron and Kenny (1986) for testing mediation effects. The linear regression included both reappraisal and positive emotions as predictors and the student-oriented approach as dependent variable. The analysis yielded a significant model, $R^{2}$ $=.18, F(2,142)=15.77, p<.001$. Both variables significantly predicted the student-oriented approach, reappraisal $\beta$ $=.29, p<.001$; positive emotions $\beta=.26, p=.001$. Sobel $Z=1.88, S E=.02, p=.06$, which indicates that a partial mediation is not unlikely.

Fourth, the analyses yielded no significant correlations with the content-oriented approach (all $|r| \mathrm{s}<.16, p \mathrm{~s}>.06$ ), with one exception: The two approaches to teaching dimensions were intercorrelated, $r(143)=-.20, p=.02$. This correlation sheds doubt about the independence of the two approaches to teaching dimensions and is a replication of previous findings with the questionnaire (e.g., Trigwell, 2012). 


\subsection{Discussion}

\subsubsection{Research Questions}

The current data allow a positive answer to Research Question 1. The new FrET questionnaire reliably assessed one scale for positive emotions and one for negative emotions during higher education teaching. In a manner very similar to established measures for the assessment of emotions (e.g. Watson, Clark \& Tellegen, 1988), the new questionnaire assessed the frequency of positive and negative emotions and minimized the influences of non-emotional item content as done in a previous study (Trigwell, 2012). However, two emotion items loaded on both positive and negative emotion factor, and one emotion item had a low loading on the expected factor. As the specifities of these emotions could explain these findings, the exceptions rather prove the general rule.

The answer to Research Question 2 is mixed. The frequency of experiencing positive emotions during teaching was positively correlated to the student-oriented approach to teaching. This result replicates previous research on emotions and approaches. The more often university teachers experienced positive emotions during their teaching, the stronger their student-oriented teaching approach. This relation seems to be robust and independent from the use of a specific emotion questionnaire. However, negative emotions were not related to either the student-oriented or to the content-oriented approach. In addition, there was no relation between negative emotions and the student-oriented approach. The large proportion of student assistants within the sample could have caused this result. The main dependent variables, the student- and the content-oriented approaches to teaching scales of the ATI questionnaire, were not originally developed with teaching assistants, but with science teachers (e.g., Trigwell \& Prosser, 2004). In addition, as the data indicated, teaching assistants experienced more positive emotions than teachers did. In order to exclude this influence, Study 2 will include only university teachers in the sample.

The answer to Research Question 3 is positive. The study, for the first time, yielded relations between a student-oriented approach to teaching and two emotion regulation strategies, cognitive reappraisal and expressive suppression. The more often the participants used reappraisal and the less often they used suppression, the stronger their student-oriented approach. One can interpret this result as supportive for the idea laid out in the theory section. Similar processes may underlie both student orientation and cognitive reappraisal: Both require taking on a specific new perspective. In order to explore this issue, Study 2 included perspective taking and other, cognitive and emotional, aspects of empathy as possible mediators. In addition, Study 1 was not decisive about whether the relation between reappraisal and the student-oriented approach was independent from positive emotions. Study 2 was done in order to clarify this latter issue as well. Interestingly, expressive suppression was not related to a reduction of positive emotions, as found by Gross and John (2003). This finding may be due to the difference between general emotional experience as researched by Gross and John (2003) and teaching-specific expression display rules as researched in the current study.

\subsubsection{Methodological Limitations}

In addition to the fact that the sample included many student assistants, other methodological issues may restrict the validity of Study 1. First, the study used a relatively small sample of participants located within one university. Study 2 will resolve this issue with a larger and, more importantly, a more diverse sample drawn from several universities. Second, the convenience sample used for the study may restrict the validity of its results. Given that participants were recruited via teaching-related email lists, it is likely that the current results may overestimate the positive emotions and the student-oriented approach to teaching, compared to a representative sample. Third, the null-relations between the variables and the content-oriented approach to teaching could have been caused by the low consistency of this scale. Although other German translations of the ATI were available at the time (e.g., Lübeck, 2009), Study 2 continued using the Braun and Hannover (2008) translation for the sake of consistency with Study 1. Fourth, the cross-sectional design does not allow for causal interpretations of the data. Emotions and emotion regulation could have influenced the approaches to teaching; the approaches could have influenced emotions and emotion regulation, or other variables could have influenced all of these. Although Study 2 did not completely resolve the problem of causality, it tested one possible mediator for the relation between reappraisal and the student-oriented approach.

\section{Study 2}

In order to replicate the findings and to clarify the issues stated in the discussion section of Study 1, Study 2 used the same methods, but with a larger sample including only higher education teachers. In addition, Study 2 , for the first time, assessed relations between higher education teachers' approaches to teaching and their degree of empathy. Previous research on teachers has found relations between emotion regulation strategies and empathy. Swartz and 
McElwain (2012), for instance, found a positive relation between preservice teachers' use of reappraisal and their perspective-taking ability: The stronger the use of reappraisal, the stronger their empathic reactions. Swartz and McElwain (2012) concluded that perspective-taking and reappraisal "may overlap" (Swartz \& McElwain, 2012, p. 221) when predicting responses to students' negative emotions. If it is true that the student-oriented approach to teaching and cognitive reappraisal rely on similar cognitive mechanisms, especially the tendency to distance onself from one's own experiences (see above), then perspective taking may be a mediator for the link between reappraisal and the student-oriented approach.

Study 2 sought answers to the following research questions:

Research Question 4: Are negative emotions correlated to the student-oriented or to the content-oriented approach to teaching?

Research Question 5: Do positive emotions mediate the relation between cognitive reappraisal and the student-oriented approach to teaching?

Research Question 6: Does empathy mediate the relation between cognitive reappraisal and the student-oriented approach to teaching?

\subsection{Methods}

\subsubsection{Sample}

$N=198$ university teachers from Southern German universities (108 female, 89 male, 1 other gender), who had been contacted via several academic development email lists, completed online questionnaires in 2014 through 2015.

\subsubsection{Questionnaires}

Participants completed basically the same questionnaires as employed in Study 1. The scale of the teacher-oriented approach to teaching that had shown a low reliability in Study 1 was used again in Study 2 order to keep it consistent with previous studies, with the expectation that a larger sample size would increase Cronbach's alpha. However, there were two exceptions to Study 1: First, the socio-demographic questionnaire only asked for participants' gender. Study 1 had shown that there was no moderation of effects by either status or teaching experience. In order to enhance participants' anonymity, the questionnaire used a reduced set of socio-demographic items. The ATI was used to differentiate a student-oriented teaching approach $(\alpha=.71)$ from a content-oriented teaching approach $(\alpha=.59)$, the emotion questionnaire was used to assess the frequency of positive emotions $(\alpha=.69)$ and negative emotions during teaching $(\alpha=.74)$, and the ERQ was used to assess emotion regulation strategies, cognitive reappraisal $(\alpha$ $=.83)$ and expressive suppression $(\alpha=.74)$.

In order to assess teachers' empathy, participants additionally completed the Interpersonal Reactivity Index (IRI) by Davis (1983) in a German version by Paulus (2009). The IRI assesses four aspects of empathy on five-point scales:

- perspective-taking, i.e. the tendency to "spontaneously adopt the psychological point of view of others" (Davis, 1983, p. 113 f.; $\alpha=.78$, example item "I sometimes try to understand my friends better by imagining how things look from their perspective");

- empathic concern, i.e. the "other oriented' feelings of sympathy and concern for unfortunate others" (Davis, 1983 , p. 114; $\alpha=.61$; example item "I often have tender, concerned feelings for people less fortunate than me");

- fantasy, i.e. the "tendencies to transpose themselves imaginatively into the feelings and actions of fictitious characters" (Davis, 1983, p. 114, $\alpha=.73$; example item "I really get involved with the feelings of the characters in a novel");

- personal distress, i.e. "self-oriented' feelings of personal anxiety and unease in tense interpersonal settings" (Davis, 1983, p. 114; $\alpha=.71$; example item "Being in a tense emotional situation scares me").

\subsection{Results}

\subsubsection{Relations between Emotions and Approaches to Teaching}

In order to answer Research Question 4, in a first step, positive and negative emotions were calculated as in Study 1. Positive emotions $(M=3.48, S D=0.63)$ were stronger than negative emotions $(M=1.89, S D=0.59), F(1,197)=$ $600.35, p<.01, \eta^{2}=.75$. In a second step, the approaches to teaching were calculated as in Study 1 . The student-oriented approach $(M=3.50, S D=0.71)$ did not differ from the content-oriented approach $(M=3.40, S D=$ $0.66)$, as yielded by a repeated-measures ANOVA, $F(1,197)=0.67, p=.41, \eta^{2}<.01$. 
Most importantly, the correlation analysis did not show a relation between negative emotions and any of the two approaches to teaching, neither with the student-oriented approach, $r(198)=-.02, p=.79$; nor with the content-oriented approach, $r(198)=-.01, p=.93$. Replicating Study 1 , the analysis yielded a significant correlation between positive emotions and the student-oriented approach, $r(198)=.46, p<.01$, but not with the content-oriented approach, $r(198)=.02, p=.78$. The more often the teachers experienced positive emotions during their teaching, the stronger their student-oriented approach to teaching. This finding replicated the non-correlation with negative emotions, again contradicting Trigwell's (2012) findings.

\subsubsection{Relations between Emotion Regulation and Approaches to Teaching}

In order to answer Research Question 5, in a first step the ERQ data were collapsed into a cognitive reappraisal $(M=$ $4.33, S D=1.14)$ and an expressive suppression score $(M=3.57, S D=1.22)$. Again, reappraisal was higher than suppression, as indicated by a repeated-measures ANOVA, $F(1,197)=37.99, p<.01, \eta^{2}=.16$. In a second step, emotion regulation strategies were correlated to approaches to teaching. Replicating Study 1, the student-oriented approach was positively related with cognitive reappraisal, $r(198)=.32, p<.01$, and negatively with expressive suppression, $r(198)=-.19, p<.01$. In a third step, a linear regression included both reappraisal and positive emotions as predictors, and the student-oriented approach as dependent variable. The analysis led to a significant model, $R^{2}$ $=.25, F(2,197)=31.76, p<.01$. Both variables significantly predicted the student-oriented approach, reappraisal $\beta$ $=.20, p<.01$; positive emotions $\beta=.40, p<.01$. Sobel $Z=3.51, S E=.02, p<.01$. This result indicates that positive emotions partially, but not fully, mediate the relation between cognitive reappraisal and the student-oriented approach to teaching. In addition, Study 2 yielded a significant correlation between the content-oriented approach and expressive suppression, $r(198)=.19, p<.01$. The stronger the content orientation, the more often teachers used suppression in order to regulate their emotions.

\subsubsection{Relations between Empathy and Approaches to Teaching}

In order to answer Research Question 6, in a first step, the IRI data were collapsed into mean scores for the four IRI subscales. Among the IRI subscales, the highest mean was found for perspective taking $(M=3.76, S D=0.61)$, followed by empathic concern $(M=3.58, S D=0.53)$, fantasy $(M=3.14, S D=0.68)$ and personal distress $(M=2.60$, $S D=0.60)$.

In a second step, the four IRI subscales were correlated with the student-oriented approach. The analysis yielded significant correlations for perspective taking, $r(198)=.17, p=.02$, empathic concern, $r(198)=.18, p=.01$, and personal distress, $r(198)=-.17, p=.02$, but not for fantasy, $r(198)=.04, p=.57$. The data imply that the more often teachers adopted others' points of view and the more often they experienced compassion or worry about other people, and the less often they experienced distress in close interpersonal situations, the stronger their student-oriented approach to teaching.

In a third step, these three IRI subscales were correlated with cognitive reappraisal. This analysis yielded significant correlations for both perspective-taking, $r(198)=.17, p=.02$, and personal distress, $r(198)=-.18, p=.01$, but not for empathic concern, $r(198)=.12, p=.10$.

In a fourth step, two linear regression analyses were run that included, as predictors, perspective taking or personal distress, respectively, and cognitive reappraisal; and the student-oriented approach as dependent variable. The analysis with perspective taking yielded a significant model, $R^{2}=.12, F(2,195)=13.58, p<.001$. Both variables significantly predicted the student-oriented approach, reappraisal $\beta=.30, p<.001$; empathic concern $\beta=.15, p=.03$. Sobel $Z=1.31, S E=.01, p=.19$. This result indicates that there was no mediation of the relation between cognitive reappraisal and the student-oriented approach to teaching by the empathic concern subscale of empathy. The analysis with personal distress, too, yielded a significant model, $R^{2}=.11, F(2,195)=12.38, p<.001$. In this model, only reappraisal significantly predicted the student-oriented approach, $\beta=.30, p<.001$; while personal distress did not, $\beta$ $=-.11, p=.10$. Sobel $Z=1.38, S E=.01, p=.17$. Personal distress did also not mediate the relation between reappraisal and the student-oriented approach.

\subsection{Discussion}

\subsubsection{Research Questions}

The answer to Research Question 4 is negative. Replicating Study 1, Study 2 found that there was no relation with negative emotions, despite the contradicting evidence by Trigwell (2012). This result, together with the similar result of Study 1, may be due to either the questionnaires used (both authors used different questionnaires) or by the different cultures contexts in which the studies were run (Trigwell used Australian teachers, whereas the current studies asked German teachers) or by a different mechanism. In order to disentangle one of the possible explanations, 
Study 3 will focus on the cultural explanation by repeating Study 1 with a sample of Australian higher education teachers.

The answer to Research Question 5 is positive. Positive emotions did mediate the relation between cognitive reappraisal and the student-oriented approach to teaching, but only partially so. It is likely that because reappraisal is effective (enhancing positive emotions), it is also linked to the student-oriented approach. The significant beta values in the regression analysis indicate, however, that part of the relation was not explained by positive emotions. The question thus remains how this relation could be explained. At least two explanations are conceivable. The methodological limitations of the current study could have artificially restricted the relations, e.g., by low internal consistencies of some of the scales. Alternatively or in addition, other, additional variables, e.g., goals or other motivational variables, could explain the additional variance. Future research could resolve this open empirical question.

The answer to Research Question 6 is negative. For the first time the study found relations between the student-oriented approach and several empathy subscales (perspective taking, empathic concern, and personal distress). The more the teachers described themselves as being able to take over another person's perspective, the stronger they felt positive emotions towards others. The less they felt negative emotions towards others, the stronger their student orientation in their teaching. However, the empathy variables did not explain the relation between reappraisal and the student-oriented approach. In other words, the common basis for both reappraisal and the student-oriented approach is still unclear.

\subsubsection{Methodological Limitations}

Although Study 2 solved some of the methodological problems of Study 1, Study 2 still yielded no significant relations between negative emotions and the content-oriented approach to teaching. This finding could be due to several factors: the low consistency of the content-orientation scale, the cultural contexts in which the studies were run, or the questionnaires employed. In addition, as in Study 1, Study 2's cross-sectional design does not allow for causal interpretations of the relations.

\section{Study 3}

Compared to Trigwell's (2012) study that had asked Australian teachers, both Study 1 and Study 2 tested German samples with a different emotion questionnaire. Thereby, the two studies confound two variables that might influence the results.

First, the questionnaire used for the emotion assessment may have made the difference. It is not unlikely that Trigwell's (2012) questionnaire overestimated the relations between negative emotions and the content-oriented approach, by including specific emotion-eliciting teaching situations and constructs other than emotions (see above). Alternatively, it could be that the participants interpreted the emotion frequency items employed in Study 1 and Study 2 less with respect to teaching, but in a more general way, like the PANAS (Watson et al., 1988).

Second, it could be that the cultural context in which the studies were run influenced the results. Several studies indicate that the "cultural-educational context" (Volet, 2001) can have a strong influence on educational processes and results. Following this idea, teachers' emotional experiences and expression may vary due to the cultural context, in addition to the specific teaching situation, part of which may be explicated as expression norms. Hagenauer, Gläser-Zikuda and Volet (2016), for instance, found in interviews that Australian teacher seemed less motivated to express negative emotions in the classroom, whereas German teachers were more open about their negative emotions, especially anger, which they described as acting more on a "professional" basis. Following this study, it could be that expressing negative emotions in the questionnaire could follow different rules in these two cultural contexts: Germany and Australia. As the data by Trigwell (2012) indicate a relation between negative emotions and a content-oriented approach to teaching in the Australian sample, Study 3 sought answers to the following research question:

Research Question 7: Are the differing results (lack of relation between negative emotions and approaches to teaching) caused by the cultural context of the studies?

\subsection{Methods}

$N=76$ university teachers from Australian and New Zealand universities (called the Australian teachers hereafter; 60 female, 15 male; 32 senior lecturer, 21 lecturer, seven reader/associate professor, 7 professor, 4 tutor/associate lecturer, 4 other) completed the questionnaires that they were asked to via an e-mail request (via the newsletter of the Higher Education Research and Development Society of Australasia, HERDSA), in 2016. Participants completed the 
same questionnaires as employed in Study 1, albeit in their English (original) versions.

\subsection{Results}

Repeated-measures ANOVAs yielded that teachers indicated stronger positive emotions as more frequently $(M=$ 3.62, $S D=0.49, \alpha=.69)$ than negative emotions $(M=2.20, S D=0.71, \alpha=.82), F(1,75)=140.50, p<.01, \eta^{2}=.56$. They also indicated a stronger student-oriented approach to teaching $(M=4.21, S D=0.50, \alpha=.68)$ than a content-oriented approach to teaching $(M=2.52, S D=0.59, \alpha=.67), F(1,75)=359.78, p<.01, \eta^{2}=.83$.

In order to answer Research Question 7, correlations were calculated between emotions and approaches to teaching. These analyses revealed positive correlations between positive emotions and the student-oriented approach, $r(76)$ $=.25, p<.01$. The more often the participants experienced positive emotions during their teaching, the stronger their student-orientated approach to teaching.

Most importantly, the analyses also revealed a relation between negative emotions and the content-oriented approach in Study 3, $r(76)=.22, p=.06$. Trigwell (2012) had found especially strong relations between the content-oriented approach and anger and boredom. The single-item correlations with the approach and anger and boredom, respectively, in the current sample were significant, anger $r(76)=.23, p=.04$, boredom $r(76)=.25, p=.03$.

\subsection{Discussion}

\subsubsection{Research Question}

The data indicate that it was rather the cultural context that influenced the result of Studies 1 and 2. The answer to Research Question 7 is positive. The hypothesis that the questionnaire employed influenced the results cannot be refuted with this data, but they seem unlikely at this moment. Australian teachers, but not German teachers, seem to experience negative emotions in dependence from their content-oriented approach to teaching. This finding could be, but does not necessarily have to be, explained with the different teaching cultures in the two countries. When looking at the means, the German samples have indicated a higher content-orientation than the Australian sample has, which may mean that Australian university teachers and their students are more used to a student-oriented teaching behaviour. Being used to student-oriented teaching methods may make it likely to experience negative emotions in the (rare) cases of a content-oriented teaching situation.

Given the strong link between the student-oriented approach to teaching and positive emotions in all three studies reported here and elsewhere (e.g., Trigwell, 2012), it is conceivable that Australian university teachers experience less negative emotions than German teachers do (e.g., Eid \& Diener, 2001). This explanation, however, is not valid, because the Australian sample indicated negative emotions as more often than the German samples did. It seems that it is not the amount or frequency of emotions experienced, but the specific emotion-eliciting situations that differ between the cultures.

\subsubsection{Methodological Limitations}

In addition to the limitations discussed for the previous two studies, the the self-selection is very likely to have taken place in Study 3, too. As participants were recruited via an academic development email list, the sample is likely to be have a stronger student-oriented approach to teaching than a representative sample might have had. In addition, this issue limits the comparison to the German samples, as the two sample procedures in the two cultures may only be similar to some extent.

\section{General Discussion}

The findings confirm the idea that approaches to teaching are based on emotional variables. If approaches to teaching are understood as attitudes, they may, in part, be based on emotional experiences during teaching. In order to demonstrate that emotion underlies approaches, experimental evidence on the formation and/or alteration of approaches would be needed. So far, alternative explanations are conceivable. Cognitive variables, like appraisals, could influence both emotions and approaches. Although the current studies do not confirm this alternative explanation (investigated with reappraisal and empathy), other cognitive or motivational variables may be more relevant. If the main idea proposed in this article holds true - that approach to teaching are in a large part based on emotional aspects -, further research may focus on their emotional aspects. Researchers may investigate, for instance, which aspects of approaches are more strongly emotion-based than others, or, whether it is the frequency or the intensity of emotional experiences which is more relevant for approaches. In addition, the emotional attitude interpretation of approaches to teaching implies research questions about the relations between emotions during teaching and teaching behavior.

By including two prominent emotion regulation strategies in the studies, the findings show additional correlates of 
the cognitive reappraisal strategy. They thereby extend the well-known positive effects of reappraisal (social functioning, well-being etc., e.g., Gross \& John, 2003) into a specific field of investigation, higher education teaching. At the moment, it is not clear how specific the emotion regulation strategies are and if there are causal relations, i.e., if emotion regulation influences approaches to teaching or vice versa or if both are affected by other factors. In addition, the studies focused on only two of several emotion regulation strategies. University teachers in the study by Hagenauer and Volet (2014a), for instance, reported the use of far more strategies than reappraisal and suppression. Further research could investigate these issues, thereby also laying pathways for recommendations for teachers on how to deal with their emotions.

Finally, the relations between empathy and approaches to teaching need mentioning. This analysis was originally meant as an investigation into cognitive mechanisms common to both the emotion reappraisal and the student-oriented approach to teaching. It turned out that several aspects of empathy, namely perspective taking, empathic concern and personal distress, were related to the student-oriented approach to teaching. On the one hand, this finding confirms the results on school teachers. Swartz and McElwain (2012), for instance, had found positive relations between reappraisal and perspective taking in preservice primary school teachers. On the other hand, the findings confirm the importance of the emotional variables, here both positive and negative (empathic concern and personal distress), in addition to cognitive variables (perspective taking). Again, the study so far only included one possible underlying mechanism. Future research may investigate the mechanisms in more detail and may focus on other possible cognitive mediators.

The present research implies a change of perspective on one of the common themes in research on higher education teaching. The emotional nature of approaches to teaching could explain the approaches' persistence and the mechanisms of their change. By endorsing emotional aspects of approaches to teaching, research will provide new options for improvement in higher education teaching.

\section{Acknowledgements}

The author would like to thank Katrijn van Oudheusden and Peter Kandlbinder for their support.

\section{References}

Abler, B. \& Kessler, H. (2009). Emotion Regulation Questionnaire - eine deutschsprachige Fassung des ERQ von Gross und John [Emotion Regulation Questionnaire - a German version of the ERQ by Gross and John]. Diagnostica, 55(3), 144-152. http://dx.doi.org/10.1026/0012-1924.55.3.144

Baron, R. M., \& Kenny, D. A. (1986). The moderator-mediator variable distinction in social psychological research: Conceptual, strategic, and statistical considerations. Journal of Personality and Social Psychology, 51, 1173-1182. https://doi.org/10.1037/0022-3514.51.6.1173

Braun, E., \& Hannover, B. (2008). Zum Zusammenhang zwischen Lehr-Orientierung und Lehrgestaltung von Hochschuldozierenden und subjektivem Kompetenzzuwachs bei Studierenden [About the relation between university teachers' approaches to teaching and teaching behavior and students' subjective competence gain]. Zeitschrift für Erziehungswissenschaft, [Sonderheft 9: Perspektiven der Didaktik], 277-291. http://dx.doi.org/10.1007/978-3-531-91775-7_18

Constanti, P., \& Gibbs, P. (2004). Higher education teachers and emotional labour. The International Journal of Educational Management, 18(4/5), 243-249. http://dx.doi.org/10.1108/01437739710156231

Davis, M. H. (1983). Measuring individual differences in empathy: Evidence for a multidimensional approach. Journal of Personality and Social Psychology, 44(1), 113-126. https://doi.org/10.1037/0022-3514.44.1.113

Deutsch, R., Smith, K. J. M., Kordts-Freudinger, R., \& Reichardt, R. (2015). How absent negativity relates to affect and motivation: an integrative relief model. Frontiers in Psychology, 6, 152. URL: http://journal.frontiersin.org/article/10.3389/fpsyg.2015.00152/abstract

[10.03.2015] http://dx.doi.org/10.3389/fpsyg.2015.00152

Eid, M., \& Diener, E. (2001). Norms for experiencing emotions in different cultures: Inter- and intranational differences. Journal of Personality and Social Psychology, 81(5), 869-885. http://dx.doi.org/10.1037//0022-3514.81.5.869

Goetz, J. L., Keltner, D., \& Simon-Thomas, E. (2010). Compassion. An evolutionary analysis and empirical review. Psychological Bulletin, 136(3), 351-374. http://dx.doi.org/10.1037/a0018807

Goetz, T., Frenzel, A. C., Hall, N. C., Nett, U. E., Pekrun. R., \& Lipnevich, A. A. (2014). Types of boredom: An 
experience sampling approach. Motivation and Emotion, 38, 401-419. http://dx.doi.org/0.1007/s11031-013-9385-y

Goetz, T., Zirngibl, A., Pekrun, R., \& Hall, N. (2003). Emotions, learning and achievement from Educational psychological perspective. In P. Mayring \& C. V. Rhoeneck (Eds.), Learning emotions. Frankfurt/M.: Peter Lang.

Grandey, A. A. (2000). Emotion regulation in the workplace: A new way to conceptualize emotional labor. Journal of Occupational Health Psychology, 5(1), 95-110. http://dx.doi.org/10.1037//1076-8998.5.1.95

Grandey, A. A. (2003). When "the show must go on": Surface acting and deep acting as determinants of emotional exhaustion and peer-rated service delivery. Academy of Management Journal, 46(1), 86-96. http://dx.doi.org/10.2307/30040678

Gross, J. J. (1998). The emerging field of emotion regulation: An integrative review. Review of General Psychology, 2(3), 271-299. http://dx.doi.org/10.1037/1089-2680.2.3.271

Gross, J. J. (1999). Emotion and emotion regulation. In L. A. Pervin \& O. P. John (Eds.), Handbook of personality: Theory and research ( $2^{\text {nd }}$ ed.) (pp. 525-552). New York: Guildford.

Gross, J. J. (2002). Emotion regulation: Affective, cognitive, and social consequences. Psychophysiology, 39, 281-291. http://dx.doi.org/10.1017.S0048577201393198

Gross, J. J., \& John, O. P. (2003). Individual differences in two emotion regulation processes: Implications for affect, relationships, and well-being. Journal of Personality and Social Psychology, 85(2), 348-362. http://dx.doi.org/ 10.1037/0022-3514.85.2.348

Hagenauer, G., Gläser-Zikuda, M., \& Volet, S. E. (2016). University teachers' perceptions of appropriate emotion display and high-quality teacher-student relationship: Similarities and differences across cultural-educational contexts. Frontline Learning Research, 4(3), 44-74. http://dx.doi.org/10.14786/flr.v4i3.236

Hagenauer, G., \& Volet, S. (2014a). "I don't hide my feelings, even though I try to": Insight into teacher educator emotion display. Australian Educational Researcher, 41, 261-281. http://dx.doi.org/10.1007/s13384-013-0129-5

Hagenauer, G., \& Volet, S. (2014b). 'I don't think I could, you know, just teach without any emotion': Exploring the nature and origin of university teachers' emotions. Research Papers in Education, 29(2), 240-262. http://dx.doi.org/10.1080/02671522.2012.754929

Johannes, C., \& Seidel, T. (2012). Professionalisierung von Hochschullehrenden. Lehrbezogene Vorstellungen, Wissensanwendung und Identitätsentwicklung in einem videobasierten Qualifikationsprogramm [Professionalization of university teachers - Teaching approaches, professional vision and teacher identity in video-based training]. Zeitschrift für Erziehungswissenschaft, $15, \quad$ 233-251. http://dx.doi.org/10.1007/s11618-012-0273-0

John, O. P., \& Gross, J. J. (2004). Healthy and unhealthy emotion regulation: Personality processes, individual differences, and life span development. Journal of Personality, 72(6), 1301-1333. http://dx.doi.org/10.1111/j.1467-6494.2004.00298.x

Kane, R., Sandretto, S., \& Heath, C. (2002). Telling half the story: A critical review of research on the teaching beliefs and practices of university academics. Review of Educational Research, 72(2), 177-228. http://dx.doi.org/10.3102/00346543072002177

Kember, D., \& Kwan, K.-P. (2000). Lecturers' approaches to teaching and their relationship to conceptions of good teaching. Instructional Science, 28, 469-490. http://dx.doi.org/10.1023/A:1026569608656

Lübeck, D. (2009). Lehransätze in der Hochschullehre [Approaches to teaching in higher education teaching]. (Doctoral thesis, Freie Universität Berlin, Berlin, Germany). Retrieved from http://www.diss.fu-berlin.de/diss/receive/FUDISS_thesis_000000011078

Meanwell, E., \& Kleiner, S. (2014). The emotional experience of first-time teaching: reflections from graduate instructors. Teaching Sociology 42(1), 17-27. http://dx.doi.org/10.1177/0092055X13508377

Mendzheritskaya, J., Hansen, M., \& Horz, H. (2015). Emotional display rules at universities in Russia and Germany. Russian Psychological Journal, 12(4), 54-77.

Meyer, J. H. F., \& Eley, M. G. (2006). The Approaches to Teaching Inventory: A critique of its development and $\begin{array}{llllll}\text { applicability. British Journal of Educational Psychology, } & \text { 76, 633-649. }\end{array}$ 
http://dx.doi.org/10.1348/000709905X49908

Ochsner, K. N., \& Gross, J. J. (2008). Cognitive emotion regulation. Insights from social cognitive and affective neuroscience. Current Directions in Psychological Science, 17(2), 153-158. http://dx.doi.org/10.1111/j.1467-8721.2008.00566.x

Paulus, C. (2009). Der Saarbrücker Persönlichkeitsfragebogen SPF (IRI) zur Messung von Empathie. Psychometrische Evaluation der deutschen Version des Interpersonal Reactivity Index [The Saarbrueck Personality Questionnaire on empathy. Psychometric evaluation of the German version of the Interpersonal Reactivity Index]. Retrieved from Saarland University Virtuelle Fachbibliothek Psychologie website: http://psydok.sulb.uni-saarland.de/volltexte/2009/2363/

Pekrun, R., Goetz, T., Frenze., A. C., Barchfeld, P., \& Perry, R. P. (2011). Measuring emotions in students` learning and performance: The Achievement Emotions Questionnaire (AEQ). Contemporary Educational Psychology, 36, 36-48. http://dx.doi.org/10.1016/j.cedpsych.2010.10.002

Postareff, L., \& Lindblom-Ylänne, S. (2011). Emotions and confidence within teaching in higher education. Studies in Higher Education, 36(7), 799-813. http://dx.doi.org/10.1080/03075079.2010.483279

Scherer, K. R. (2005). What are emotions? And how can they be measured? Social Science Information, 44(4), 695-729. http://dx.doi.org/10.1177/0539018405058216

Stupnisky, R. H., Pekrun, R., \& Lichtenfeld, S. (2014). New faculty members' emotions: a mixed-method study. Studies in Higher Education. http://dx.doi.org/10.1080/03075079.2014.968546

Swartz, R. A., \& McElwain, N. L. (2012). Preservice teachers' emotion-related regulation and cognition: Associations with teachers' responses to childrens' emotions in early childhood classrooms. Early Education \& Development, 23(2), 202-226. http://dx.doi.org/10.1080/10409289.2012.619392

Teven, J. J. (2007). Teacher temperament: Correlates with teacher caring, burnout, and organizational outcomes. Communication Education, 56, 3, 382-400. http://dx.doi.org/10.1080/03634520701361912

Topolinski, S., \& Strack, F. (2015). Corrugator activity confirms immediate negative affect in surprise. Frontiers in Psychology, 6, 34, 1-8. http://dx.doi.org/10.3389/fpsyg.2015.00134

Trigwell, K. (2012). Relations between teachers' emotions in teaching and their approaches to teaching in higher education. Instructional Science, 40, 607-621. http://dx.doi.org/10.1007/s11251-011-9192-3

Trigwell, K., \& Prosser, M. (1996). Changing approaches to teaching: A relational perspective. Studies in Higher Education, 21(3), 275-284. http://dx.doi.org/10.1080/03075079612331381211

Trigwell, K., \& Prosser, M. (2004). Development and use of the Approaches to Teaching Inventory. Educational Psychology Review, 16, 409-426. http://dx.doi.org/10.1007/s10648-004-0007-9

Volet, S. (2001). Understanding learning and motivation in context: A multi-dimensional and multi-level cognitive-situative perspective. In S. Volet \& S. Järvelä (Eds.), Motivation in learning contexts: Theoretical advances and methodological implications (pp. 57-82). Elmsford, NY, US: Pergamon Press.

Watson, D., Clark, L. A., \& Tellegen, A. (1988). Development and validation of brief measures of positive and negative affect: The PANAS scales. Journal of Personality and Social Psychology, 54(6), 1063-1070. https://doi.org/10.1037/0022-3514.54.6.1063

Zhang, Q., \& Zhu, W. (2008) Exploring emotion in teaching: Emotional labor, burnout, and satisfaction in Chinese higher education. Communication Education, 57(1), 105-122. http://dx.doi.org/10.1080/03634520701586310 